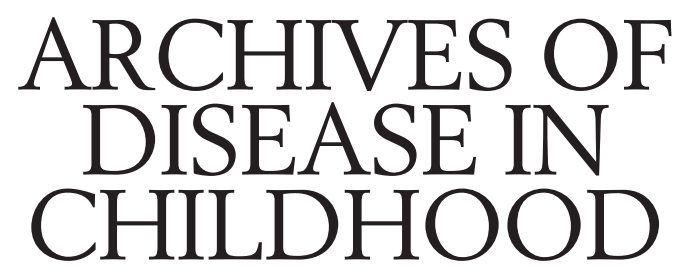

The fournal of the Royal College of Paediatrics and Child Health

\title{
Infant feeding causes all cases of asthma, eczema, and hay fever. Or does it?
}

If one does not feed babies, one can be absolutely certain that they will not develop atopic disease-clear proof of the dangers of infant feeding. The logic of this statement may seem a little fuzzy, but medical journals abound with this sort of nonsense, especially when it comes to the topic of infant feeding and allergy.

Unusually, this issue contains a paper that will save lives - not babies' but midwives'. ${ }^{1}$ The received wisdom, more of a religious belief than a scientific fact, has been that a single bottle of milk formula is enough to totally destroy the delicate balance of the infant's protective immune system, leading to the very worst atopic mayhem that the forces of the immune system can muster. This idea gathered momentum as a result of gently massaged intervention studies that-for example, classified respiratory symptoms as "cough" in breast fed babies but as "wheezing/asthma" in bottle fed babies; the so called unblinded observer method. Bolstered by this sort of data, the hunt was on for midwives who allowed breast fed newborns so much as a sniff of a bottle of milk formula. (A sniff was enough to cause trouble, for it was known that minute particles passing through the atmosphere, known as osmyls, are enough to provoke an allergic reaction; a phenomenon that is well known to subjects with severe fish allergy who react when walking past a fish and chip shop. ${ }^{2}$ ) For the "single bottle missionaries" no punishment short of the death penalty was sufficient for midwives who allowed the breast fed baby a taste of the forbidden formula.

Those who preferred data to religious belief have had a hard time. Somewhat contrary to the notion that breast feeding is protective against allergy and atopic disease, it is now well recognised that ingested food antigens can pass into human milk and provoke atopic disease..$^{2-4}$ Maternal avoidance of the food in question is followed by remission of atopic disease in the infant, and re-exposure followed by relapse. ${ }^{4}$ Many mothers susceptible to this problem are themselves atopic, and thus the women who would most wish to prevent atopic disease in their offspring may be the very ones in whom breast feeding contributes to the production of atopic disease. One prospective study showed a steadily increasing incidence of atopic disease the longer a mother exclusively breast fed her infant. ${ }^{5}$ Another prospective study of breast fed babies showed that those who had been exclusively breast fed in the first few days of life were considerably more likely to develop atopic disease than those who were given supplementary cows' milk feeds for the first few days of life and then breast fed. ${ }^{6}$ Furthermore, a follow up study of 69 preterm infants showed that the 38 infants fed exclusively with human milk to the age of four months had significantly more allergic symptoms than the 31 infants fed with adapted cows' milk formula from birth. ${ }^{7}$ Of course there are plenty of studies to suggest the reverse-that is, that breast feeding is protective. A selective trawl of the literature can be made to reveal data to support any point of view.

This issue reports a study in which 1533 breast fed neonates were randomised to receive either cows' milk protein or a placebo mixture of maltodextrin, glucose, and mineral solution emulsified with vegetable fats. ${ }^{1}$ The intervention feeding was given at least three times during the first three days of life, supplementary to or instead of a breast feed. Mothers were encouraged to breast feed for at least six weeks, and the babies were followed for two years. Atopic disease in the first year was found in $10.0 \%$ of those who received the cows' milk and $9.3 \%$ of those who received the placebo, a relative risk of 1.07 . In the second year the figures were $9.6 \%$ and $10.2 \%$, a relative risk of 0.94 . This carefully performed and large randomised controlled study effectively heralds the end of the death penalty for midwives who offer infant milk formula to breast fed infants.

Apparent safety of a formula "top up" is one thing, desirability is quite another matter. To the milk formula industry who funded this study, the results may be welcome (one hopes that the vegetable fats of the placebo did not include peanut oil). To me, however, the final paragraph of the discussion opens with a shocking sentence. "To give some formula before breast feeding is established is often practised and sometimes even indicated" (my emphasis).

I accept that giving formula at this time is sometimes "even indicated" but I am most unhappy about the fact that it is "often practised". I cannot speak for the Netherlands, but certainly in the UK "often practised" is sadly true. This implies a continuing and widespread misunderstanding about how normal breast feeding is established in humans, and is evidence that many health professionals are on shaky ground when giving practical advice to mothers who wish to breast feed. A middle class solution is to close 
the door to the health visitor and call in someone who has breast fed a few infants herself and has been trained to give practical advice to others (for example, a National Childbirth Trust breast feeding counsellor); however, this strategy is not available to most mothers.

The sad fact is that many health professionals are no more equipped to breast feed than they are to give practical advice on the subject.

University Department of Child Health,

T J DAVID

Booth Hall Children's Hospital,

Manchester M9 7AA, UK
1 de Jong MH, Scharp-van der Linden VTM, Aalberse RC, Oosting J, Tijssen JGP, de Groot CJ. Randomised controlled trial of brief neonatal exposure to cows' milk on the development of atopy. Arch Dis Child 1998;79:126-30. 2 David TJ. Food and food additive intolerance in childhood. Oxford: Blackwell Scientific Publications, 1993.

3 Gerrard JW. Allergy in breast fed babies to ingredients in breast milk. Ann Allergy 1979;42:69-72.

4 Cant AJ, Bailes JA, Marsden RA, Hewitt D. Effect of maternal dietary exclusion on breast fed infants with eczema: two controlled studies. BMF 1986;293:231-3.

5 Savilahti E, Tainio VM, Salmenpera L, Siimes MA, Perheentupa J. Prolonged exclusive breast feeding and heredity as determinants in infantile Prolonged exclusive breast feeding and
atopy. Arch Dis Child 1987;62:269-73.

atopy. Arch Dis Child 1987;62:269-73.
6 Lindfors A, Enocksson E. Development of atopic disease after early administration of cow milk formula. Allergy 1988;43:11-16.

7 Savilahti E, Tuomikoski-Jaakkola P, Jarvenpaa AL, Virtanen M. Early feeding of preterm infants and allergic symptoms during childhood. Acta Paediatr 1993;82:340-4 